\title{
Replacement Therapy in Patients with Von Willebrand Disease-Indications and Monitoring
}

\section{Die Substitutionsbehandlung des von-Willebrand- Syndroms-Indikationen und Monitoring}

\author{
Ulrike Nowak-Göttl ${ }^{1}$ Wolfgang Miesbach ${ }^{2}$ Jürgen Koscielny ${ }^{3} \quad$ Carl-Erik Dempfle $^{4} \quad$ Marc Maegele $^{5}$ \\ Mario von Depka Prondzinski ${ }^{6}$ Dagmar Westrup ${ }^{7}$ Michael Spannagl ${ }^{8}$
}

\footnotetext{
1 Department of Clinical Chemistry, Thrombosis and Hemostasis Unit, University Hospital of Kiel and Lübeck, Kiel, Germany

2 Medical Clinic II, Institute of Transfusion Medicine, Goethe

University, Frankfurt, Germany

${ }^{3}$ Institute of Transfusion Medicine, Charité - University Medicine, Berlin, Germany

${ }^{4}$ Coagulation Center Mannheim, Mannheim, Germany

${ }^{5}$ Department of Trauma and Orthopedic Surgery, Cologne-Merheim Medical Center, University of Witten/Herdecke, Cologne, Germany

${ }^{6}$ Werlhof-Institute Hannover, Hannover, Germany

${ }^{7}$ Bad Camberg, Germany

8 Department of Hemostasis and Transfusion Medicine, Ludwig-

Maximilians University, Munich, Germany

Hämostaseologie 2019;39:326-338.
}

Abstract
Keywords
- von Willebrand
disease
- von Willebrand factor
- factor VIII
- replacement therapy
- bleeding

Address for correspondence Ulrike Nowak-Göttl, Dr. med, University Hospital Schleswig-Holstein, Institute of Clinical Chemistry,

Thrombosis \& Hemostasis Treatment Center, Campus Kiel \& Lübeck, Germany (e-mail: leagottl@uksh.de).
In patients with von Willebrand disease (VWD), replacement therapy may be indicated in the case of spontaneous bleeding, surgical interventions and injuries/trauma or as a prophylaxis of spontaneous bleeding episodes. The deficient von Willebrand factor (VWF) is replaced with or without factor VIII (FVIII). Dual VWF/FVIII concentrates can be beneficial in the case of low FVIII level, while repeated dosing may lead to very high FVIII levels, with a potential thrombogenic effect in individual VWD patients. An excessive FVIII:C increase can be limited by using a VWF product with a low level of FVIII, achieving a haemostatic adequate FVIII:C increase after 6 to 12 hours. Replacement therapy in patients with VWD shall be individualised considering VWD type, history and risk of bleeding and risk of thrombosis, as well as indication and the individually variable VWF and FVIII increase. Deviations from the dosages and minimum trough levels mentioned in guidelines or recommendations can be considered in justified cases. The objective of this review is to provide recommendations for specific constellations of replacement therapy based on the VWD-specific guidelines available in Europe, the available evidence, own experiences and the consensus of the interdisciplinary German author group. received

October 30, 2018

accepted after revision

May 13, 2019 (c) 2019 Georg Thieme Verlag KG Stuttgart · New York
DOI https://doi.org/

10.1055/s-0039-1692688.

ISSN 0720-9355. 


\section{Zusammenfassung}

\section{Schlüsselwörter}

- von-WillebrandSyndrom

- von-WillebrandFaktor

- Faktor VIII

- Substitutionstherapie

- Blutung
Bei Patienten mit von-Willebrand-Krankheit (VWD) kann eine Ersatztherapie bei spontanen Blutungen, chirurgischen Eingriffen und Verletzungen/Traumata oder zur Prophylaxe spontaner Blutungen angezeigt sein. Der mangelnde von Willebrand-Faktor (VWF) wird mit oder ohne Faktor VIII (FVIII) ersetzt. Duale VWF/FVIII-Konzentrate können bei niedrigem FVIII-Spiegel von Vorteil sein, während eine wiederholte Gabe zu sehr hohen FVIII-Spiegeln führen kann, die bei einzelnen VWD-Patienten einen potenziellen thrombogenen Effekt haben können. Ein übermäßiger Anstieg von FVIII: C kann durch die Verwendung eines VWF-Produkts mit einem niedrigen FVIII-Gehalt begrenzt werden, wodurch nach 6 bis 12 Stunden ein hämostatisch adäquater Anstieg von FVIII:C erreicht wird. Die Ersatztherapie bei Patienten mit VWD ist unter Berücksichtigung des VWD-Typs, der Vorgeschichte, des Blutungsrisikos und des Thromboserisikos sowie der Indikation und des individuell variablen Anstiegs von VWF und FVIII zu individualisieren. Abweichungen von den in Richtlinien oder Empfehlungen genannten Dosierungen und Mindest-Talspiegeln können in begründeten Fällen berücksichtigt werden. Ziel dieser Übersichtsarbeit ist es, Empfehlungen für spezifische Konstellationen der Ersatztherapie auf der Grundlage der in Europa verfügbaren VWD-spezifischen Leitlinien, der verfügbaren Evidenz, der eigenen Erfahrungen und des Konsenses der interdisziplinären deutschen Autorengruppe zu geben.

\section{Introduction}

Von Willebrand disease (VWD) is a quantitative (type 1, type 3 ) or qualitative (type 2) impairment of von Willebrand factor (VWF). ${ }^{1}$ VWD can be congenital or acquired and impairs haemostasis by:

- Interference with VWF-mediated platelet binding to the subendothelium in situations of vascular damage (primary haemostasis).

- The coagulation process caused by a deficiency of circulating FVIII, ${ }^{2}$ which is rapidly cleared from the circulation if not bound to VWF (FVIII/VWF ratio: $1: 50$ ). ${ }^{3}$

Mediation of platelet adhesion and aggregation depends particularly on high-molecular-weight VWF multimers (5,500-10,000 kDa), while FVIII binding can also be achieved with low-molecular-weight VWF multimers (500-2,500 kDa). ${ }^{4}$

The diagnosis of VWD and subtypes is made based on a conspicuous own or family history of bleeding with confirmation using appropriate laboratory tests as described elsewhere in detail. ${ }^{5}$ The diagnostics should include antigen (Ag) and function tests at a plasma and platelet level [VWF:Ag, VWF:Ristocetin cofactor (VWF:RCo) or test variants, VWF:collagen binding (VWF:CB) and factor VIII coagulant (FVIII:C)], might need further subtyping tests such as assays of VWF multimers and Ristocetin-induced platelet aggregation, and can be substantiated by molecular genetic examinations. ${ }^{6}$ The severity of clinical tendency to bleed does not necessarily correlate with the VWD type and laboratory results. ${ }^{7,8}$ Patients with VWD should be equipped with an emergency health card that is updated on a regular basis.

\section{Therapeutic Options}

In addition to supportive measures (e.g., tranexamic acid especially in the case of mucosal bleeding, oral contraception in the case of menorrhagia, iron replacement), the following treatment options can be considered:

- Mobilisation of stored VWF using desmopressin (1-desamino-8-d-arginine vasopressin, DDAVP).

- Replacement of deficient VWF with or without the addition of FVIII.

Since endogenous FVIII production is intact in the case of congenital or acquired forms, the lack of circulating FVIII can be compensated if sufficient functional VWF is made available in the plasma.

In patients with VWD type 1, DDAVP is effective in most cases. DDAVP can be contraindicated in type 2B and, of note, DDAVP is not useful in type 3 cases. Whenever possible, a DDAVP test infusion should be given prior to the initiation of treatment to investigate the individual response. $^{9}$ If DDAVP is repeated after a short interval, tachyphylaxis (reduced efficiency due to empty endothelial stores) and the increased risk of hyponatremia and subsequent seizures especially in young children must be considered, respectively avoided by adequate fluid restriction.

Replacement treatment with VWF can be indicated in patients with VWD in the following situations:

- Spontaneous bleeding.

- Surgical procedures.

- Injury/trauma.

- Prophylaxis of spontaneous bleeding. 
The recommendations for replacement treatment in patients with VWD are given below. These are based on a selective literature review (1987 till 2017), considering the guidelines/recommendations and the consensus of the interdisciplinary German author group.

\section{Licensed Products for Replacement Therapy in Patients with VWD in Germany}

The following products are available for individualised replacement therapy:

- Dual concentrates (FVIII products containing VWF).

- Highly purified VWF products (Willfact) with a very low FVIII content and Veyvondi, a recombinant human VWF product with only traces of FVIII. ${ }^{10}$

The use of dual VWF/FVIII products prevails in Germanspeaking countries. Dual VWF/FVIII products are beneficial when the FVIII levels are low. ${ }^{9}$ This might depend on VWF type/subtype and clinical situation, such as acute bleeding or emergency surgery, when usage of free combinations of a VWF and FVIII product does not seem feasible, as well as ondemand treatment of acute bleeding in the self-treatment setting at home or on vacation.

When FVIII levels are normal, the risk of thromboembolism should be taken into consideration if supraphysiological FVIII concentrations are induced by the exogenously added FVIII. ${ }^{9,11}$ With repeated administration of dual concentrates, accumulation may occur due to the overlapping of exogenously administered FVIII and the formation of endogenous VWF-stabilized FVIII. ${ }^{9,11,12}$ For longer treatment periods ( $>24-48$ hours), a dose reduction and/or prolongation of the dosing interval-considering the clinical efficacy of the VWF level-or switching to a VWF concentrate with a low FVIII portion is recommended. ${ }^{12-15}$

To avoid an excessive FVIII:C increase after replacement, a highly purified plasma-derived VWF product with a low FVIII portion is available (-Table 1 ). A recombinant VWF with only traces of FVIII recently received market authorization. ${ }^{16}$ If VWF with a low or without FVIII is injected, a haemostatically adequate FVIII:C increase is usually achieved after 6 to 12 hours by stabilization of the patients' endogenously formed FVIII ( - Fig. 1). ${ }^{17,18}$

In a prospective study of patients with different types of clinically severe VWD, very good clinical outcomes were achieved with highly purified VWF concentrates for both spontaneous bleeding episodes and surgical interventions. An additional dose of FVIII was given for the first infusion in $38 \%$ of the spontaneous bleeding episodes and $12 \%$ of the surgical interventions. ${ }^{22}$

The products listed in -Table 1 are licensed options available in Germany for replacement therapy in patients with VWD. Important parameters for product selection include:

- Manufacturing process (purification, virus inactivation and elimination).

- VWF to FVIII ratio.
- VWF:RCo to VWF:Ag ratio.

- Storage and stability.

Regarding the terminal half-life of VWF:RCo, the dual preparations show large individual ranges of variation (e.g., $2.8-51.1$ hours), ${ }^{12-15,19}$ which is one of the reasons for individualized dosages.

Depending on the manufacturing process of plasma-derived VWF products, the function of VWF may be impaired by a loss of higher molecular weight proteins. Therefore, products with a VWF:RCo/VWF:Ag ratio $>0.7$ should be favoured. $^{23}$ The recombinant VWF product contains beside physiologically occurring plasmatic multimer structures also ultra-large multimers. ${ }^{16}$

The product dosage should be based on the VWF:RCo level. ${ }^{23}$ In this context, 1 IU of VWF:RCo/kg raises the VWF plasma level by an average of 1.7 to $2.1 \%{ }^{16-18,24-26}$

\section{Monitoring of Replacement Therapy}

Monitoring is indicated during replacement therapy with $\mathrm{VWF}^{27}$ Historically, the focus was on the sole monitoring of FVIII. Meanwhile, more automated and standardised tests for measuring VWF activity (VWF:RCo or test variants) are available, which are additionally recommended for individual treatment management, although this is discussed controversially. $^{28,29}$ For major surgical procedures, FVIII and VWF activity should be monitored daily for at least 1 week; at least once for minor surgical procedures. An in vivo recovery determined pre-operatively can predict the FVIII:C and VWF activity levels achieved peri- and postoperatively only to an insufficient extent. ${ }^{30}$

The target levels should be defined individually depending on VWD type, underlying disease and clinical situation, as well as other factors which may be considered, such as age and $\mathrm{ABO}$ blood type, accounting for varying reference ranges. ${ }^{31}$ In addition to dosages, guidelines and recommendations also indicate minimum trough levels for orientation (-Table 2).

\section{Possible Clinically Relevant Side Effects of Replacement Therapy}

Hypersensitivity or allergic reactions occur rarely outside inhibitor development when using coagulation factor products.

Registry data and case series with small sample sizes point out the possible formation of inhibitors, the incidence of which is approximately $4 \%$ and almost exclusively in type 3 VWD. ${ }^{33-35}$ Inhibitors whose titres are sometimes high can be directed against VWF or FVIII ${ }^{35,36}$ and can lead to an inadequate clinical response. Anaphylactic reactions are possible at the same time as inhibitor development. Genetic predisposition, ${ }^{36}$ FVIII content, product type and dosage are discussed as factors which may influence inhibitor development. ${ }^{35}$

In the normal population, increased FVIII levels $>150 \%$ are considered as risk factors for venous thromboembolism 


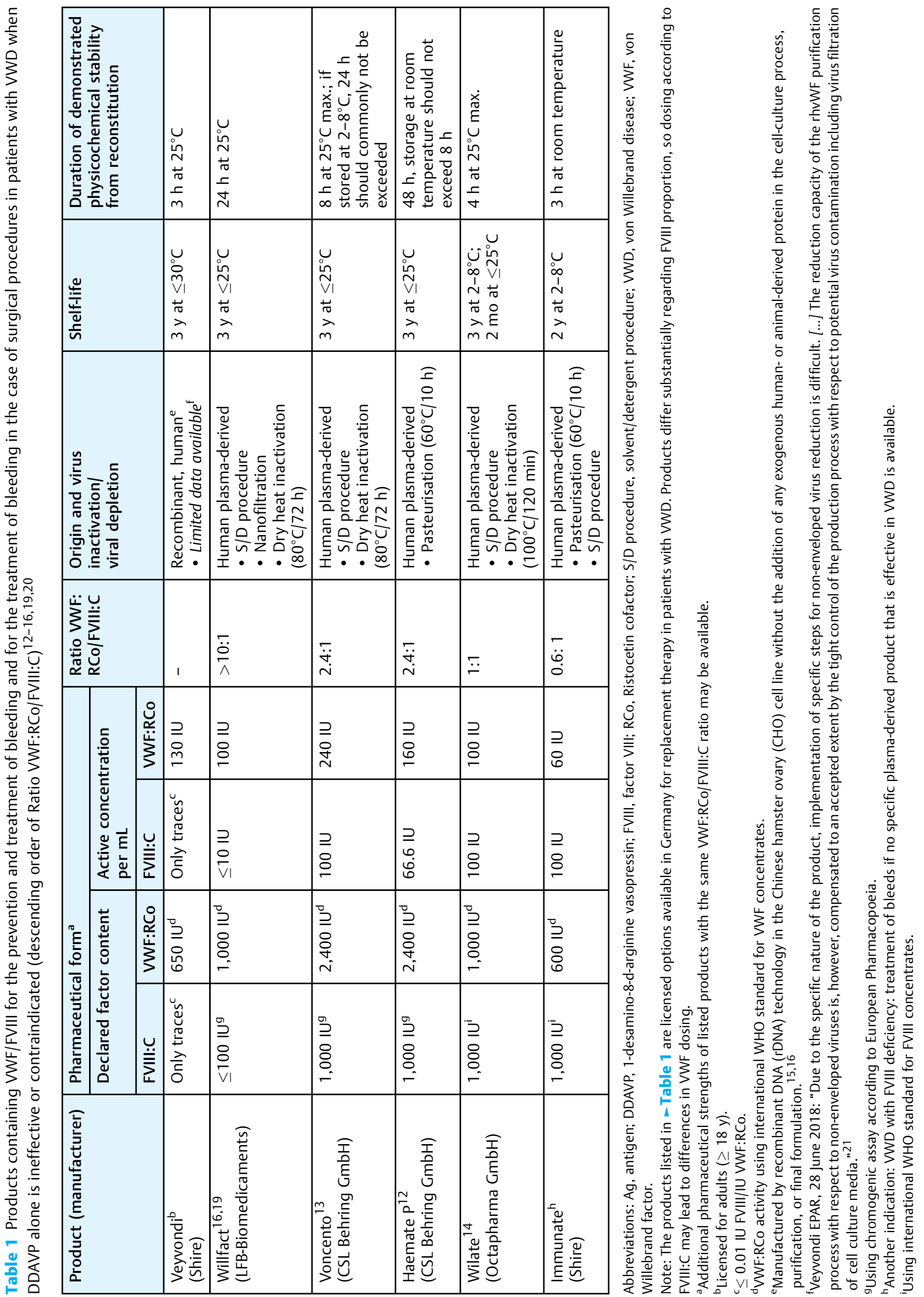



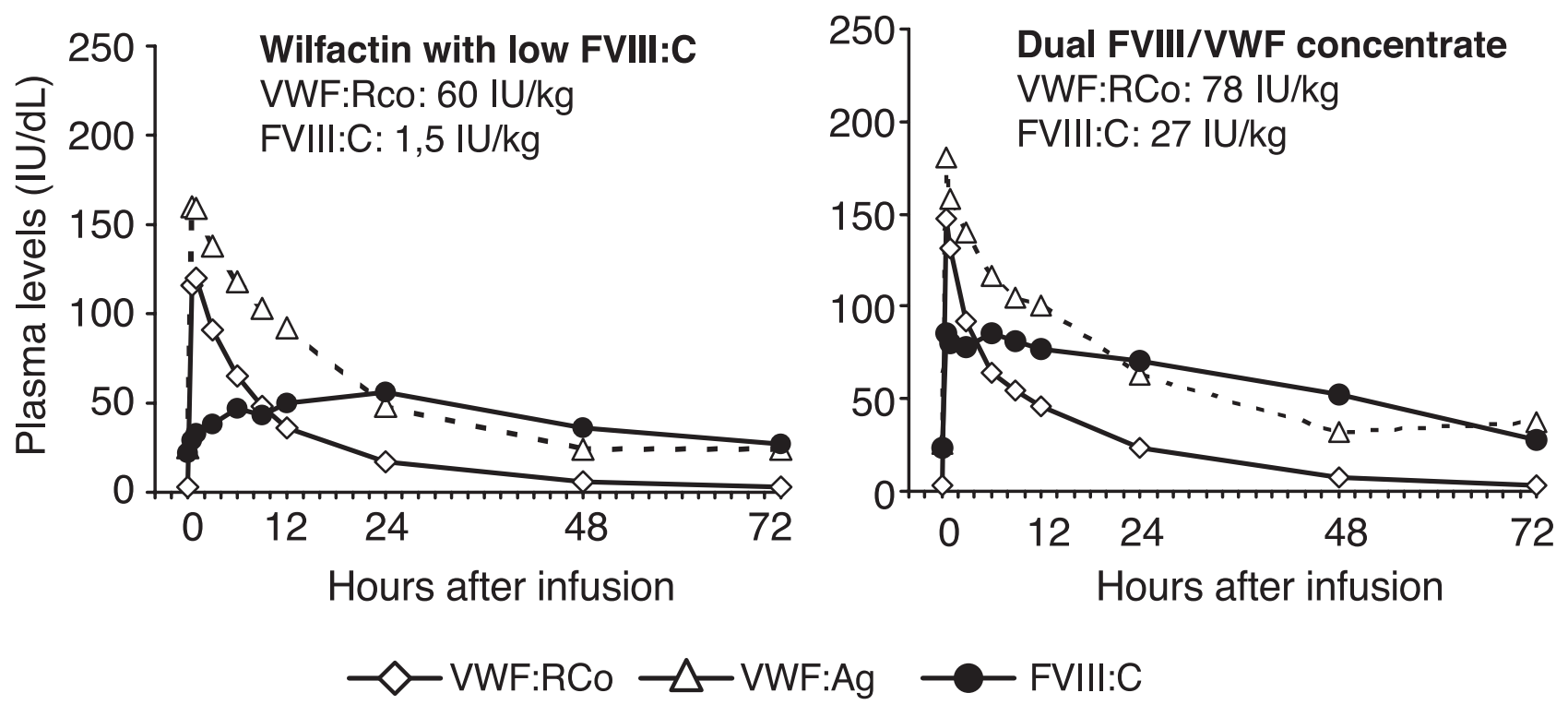

Fig. 1 Median plasma levels of VWF:RCo, VWF:Ag and factor VIII:C after single-dose administration of Wilfactin (equivalent to Willfact) or a dual FVIII/VWF concentrate in patients with severe VWD (modified from Goudemand et al ${ }^{17}$ ). Ag, antigen; FVIII, factor VIII; RCo, Ristocetin cofactor; VWF, von Willebrand factor.

(VTE), and increased VWF levels $>200 \%$ as risk factors for arterial vascular complications. ${ }^{37,38}$ In VWD patients with an increased VTE risk during replacement therapy, ${ }^{39}$ very high FVIII levels may also have a thrombogenic effect: a FVIII:C > 200\% was documented in three out of five VWD patients on dual-replacement therapy and FVIII:C level monitoring at the time of a VTE. ${ }^{11}$ In case studies, treatment with a dual VWF/FVIII product was mentioned as the most common VTE risk factor. ${ }^{40}$ After replacement with a dual VWF/FVIII product, two thrombotic events occurred related to transiently increased FVIII levels during surgical interventions in two clinical trials. ${ }^{41}$ VWD patients with evidence of increased acute-phase proteins, a history of thrombosis, pregnancy, old age or congenital risk factors of thrombosis are particularly at risk. ${ }^{42}$ However, bleeding risk in VWD patients with the need for replacement therapy is certainly higher than thrombotic risk caused by replacement therapy. ${ }^{11,43}$

\section{Prophylaxis of Thrombosis in Surgical Interventions}

General guidelines on thrombosis prophylaxis [e.g., German S3 guideline 'Prophylaxis of venous thromboembolism (VTE)' $]^{44}$ are not sufficient for VWD: on the one hand, VWD increases the risk of bleeding so that the benefit-risk ratio of anticoagulation worsens, and, on the other hand, activities used to achieve haemostasis can increase the risk of thrombosis.

In patients with VWD:

- Pharmacological VTE prophylaxis should be discussed in addition to physical measures,

- Pain management should be limited to analgesics without impairment of platelet function.
- The reactive postoperative increase in FVIII should be monitored on a regular basis. A change of preparation to a VWF product with less FVIII may be indicated.

\section{International Guidelines and Expert Recommendations in German-Speaking Countries}

To date, there is no German guideline specifically for the treatment of VWD. The cross-sectional guidelines issued by the German Medical Association contain general recommendations on the therapeutic use of blood components and plasma derivatives. ${ }^{27}$ VWD is mentioned together with haemophilia A, so that only dual concentrates are mentioned rather than VWF products with a very low FVIII content. Special aspects regarding VWD have not been dealt with in these cross-sectional guidelines so far.

In addition to a U.S. guideline on VWD, ${ }^{45}$ four VWDspecific guidelines or recommendations have been published in Europe (-Table 2). The high variability in the clinical manifestation of $\mathrm{VWD}^{28}$ requires individualised treatment concepts, which should also be aimed outside large treatment centres. Patients with VWD should be managed in cooperation with a haemophilia centre and with access to a local coagulation laboratory. ${ }^{28}$

\section{Treatment of Spontaneous Bleeding}

In a cohort of 796 patients, approximately one in 10 patients with VWD required DDAVP and/or replacement therapy at least once a year for a bleeding episode, especially patients with VWD type 3 and $2 A .^{8}$ In patients with VWD type 3 , only replacement therapy is possible. Replacement therapy may also be required in patients with VWD type 1 or type $2 .{ }^{8}$

Overall, mucosal bleeds are more frequent than haematoma and joint bleeds. Epistaxis and menorrhagia occur in all 


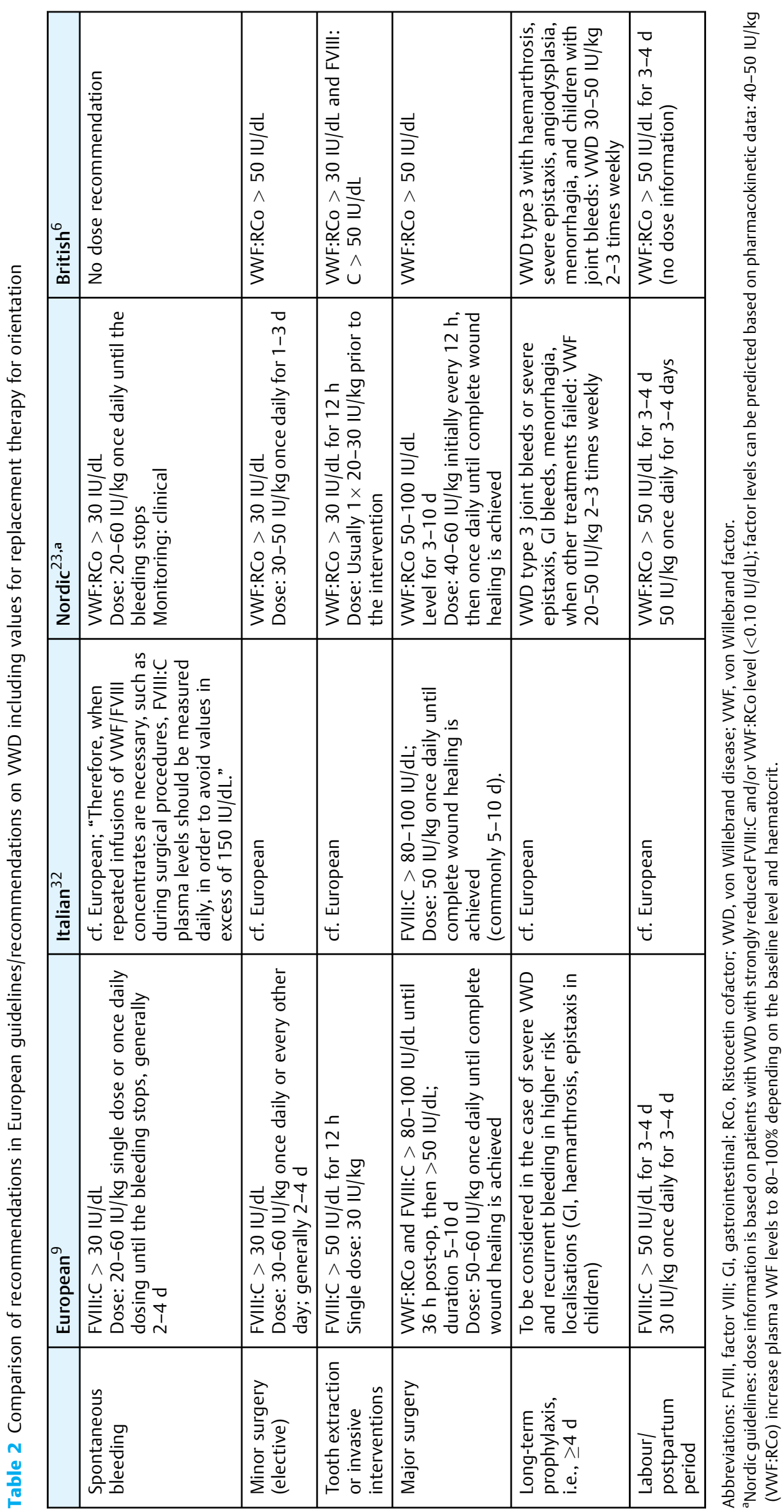


VWD types, whereas gastrointestinal (GI) bleeding is seen mainly in VWD type 3 and VWD type $2 \mathrm{~A}$, which are characterized by partial or complete loss of intermediate- and highmolecular-weight VWF multimers. ${ }^{8}$ GI bleeding represents a severe manifestation of bleeding in VWD, angiodysplasia being a major cause. ${ }^{46}$ High-molecular-weight structures of VWF appear to influence angiogenesis, and loss of such structures may cause vascular malformation, especially in VWD type 2A and acquired VWD of cardiogenic origin. ${ }^{47}$ On the other hand, haematomas and joint bleeds occur mainly in VWD type 3 and in those patients with more severe VWD type 1 characterized by lower FVIII levels. ${ }^{8}$

VWF/FVIII products as well as the highly purified and the recombinant VWF product demonstrated good or excellent efficacy in approximately 89 to $98 \%$ of spontaneous bleeding episodes. ${ }^{18,22,24,48,49}$ The dose requirement of replacement therapy is highest in GI bleeding.

\section{Treatment of Traumatic Bleeding}

The European guidelines or recommendations do not contain separate statements on replacement therapy for traumarelated bleeding., ${ }^{6,9,23,32}$ The information on bleeding episodes focus either on spontaneous bleeding ${ }^{8,11,31}$ or more

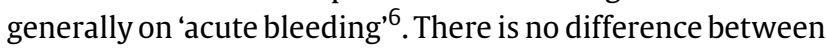
the procedures for spontaneous or traumatic bleeding, except that with traumatic bleeding, surgical intervention may follow.

\section{Treatment of Acute Bleeding}

In addition to general recommendations of transfusion medicine and administration of anti-fibrinolytics, doses of 20 to $60 \mathrm{IU} / \mathrm{kg}$ VWF:RCo depending on the localisation, once or twice daily, are recommended for replacement therapy until the bleeding has stopped. As a rule, a 2- to 4-day replacement therapy is generally recommended. ${ }^{9}$ In the case of repeated dosing, the FVIII:C should be monitored to avoid persistent FVIII:C levels $>200 \%$, or a VWF product with a low FVIII level should be considered. In GI bleeding due to angiodysplasia, 40 to $60 \mathrm{IU} / \mathrm{kg}$ once or twice daily are recommended until the bleeding has stopped..$^{50}$ The duration of treatment is generally longer than those with other VWD-associated bleeds. ${ }^{49}$ If GI bleeding is suspected, patients should be hospitalised. A VWF:RCo of $>30 \%$ does not exclude spontaneous bleeding. Higher VWF activities may be required depending on the VWD type and phenotype of bleeding. In acute spontaneous bleeds or traumatic haemorrhage, the initial treatment must include FVIII in addition to VWF if the FVIII trough levels are inadequate and usage of a dual VWF/FVIII concentrate could be recommended.

\section{Procedure for Elective Surgical Procedures}

In VWD patients, the need for replacement therapy should be reviewed in cases of planned and elective surgery. In approximately $95 \%$ of cases with such indication, replacement therapy was judged to be effective. ${ }^{51}$

Large orthopaedic interventions on target joints require special attention. Target joints are joints with recurrent bleeding due to anatomic modifications (e.g., neovascular- isation). ${ }^{52}$ Retrospective analysis of a cohort with 126 major joint surgeries revealed bleeding complications in $18 \%$ of interventions - the risk of bleeding was higher than average in patients without replacement $(33 \%)$ and in patients without FVIII monitoring (26\%). ${ }^{52}$

\section{Recommendations in Patients Undergoing Surgery}

Close cooperation between the surgeon and haematologist must be ensured, ${ }^{38}$ and therapy must be adjusted according to the current guidelines and to the individual and dynamic bleeding situation ( - Table 2). For elective procedures, an individualised replacement and monitoring plan (FVIII and VWF activity) should be prepared, with a higher initial dose and subsequent individualised maintenance doses. ${ }^{38}$ In emergency surgery requiring replacement therapy, the initial treatment should also include FVIII in addition to VWF to achieve an immediate increase in FVIII levels. In the case of elective surgery, a VWF product with a low FVIII level can be administered if the basal FVIII level is adequate or the first dose is given at least 12 to 24 hours prior to the start of surgery. In this case, an adequate FVIII level can be expected because of endogenous FVIII synthesis. ${ }^{17}$ In general, patients with VWD type 3 and 2B in particular require replacement therapy for minor surgical procedures (e.g., biopsies, catheter placements, dental surgery or laparoscopic procedures), whereas in type 1,2A, 2M and 2N, DDAVP is the treatment of choice if the response is good. ${ }^{38}$ Major elective surgical interventions are a possible indication for a VWF concentrate with a low FVIII level, especially if multiple doses are anticipated in patients with an increased risk of thrombosis. ${ }^{9,32}$

\section{VWD and Prophylaxis}

Long-term prophylaxis in VWD is being used increasingly common $^{53}$ to prevent secondary complications, reduce hospitalization, and improve quality of life. ${ }^{34,54,55}$ Due to the late onset of clinically relevant bleeding, prophylaxis in patients with VWD is usually secondary prophylaxis, ${ }^{35,53}$ which is started in early adulthood. ${ }^{54}$ Bleeding scores can help to assess the severity of bleeding tendency. ${ }^{23,56}$

Indications for prophylaxis may be severe VWD with recurrent forms of GI bleeding, joint bleeding, severe nose bleeding, menorrhagia and in cases which could not adequately controlled with other therapeutic options. $6,9,23$

If joint bleeds occur, an early start of secondary prophylaxis, e.g., at the age of $<5$ years, is beneficial to prevent arthropathy. ${ }^{34}$ A VWF dose of 30 to $50 \mathrm{IU} / \mathrm{kg}$ two to three times a week is usually required. ${ }^{33}$ In women with type 1 VWD suffering from menorrhagia, replacement therapy is required in approximately $1 \% .{ }^{57}$ To reduce blood loss due to menorrhagia resistant or not amenable with oral estroprogestinic pill, VWF doses of 33 to $95 \mathrm{IU} / \mathrm{kg}$ were used in women with VWD for 1 to 6 days per cycle. ${ }^{57}$

Prophylaxis with VWF-containing concentrates is the most efficient method to prevent recurrent GI bleeding, ${ }^{46}$ often requiring three or more doses per week. ${ }^{58}$ The combination with oral tranexamic acid seems wise in the case of GI bleeding. $^{23}$ 


\section{Recommendations for Long-Term Prophylaxis}

- Long-term prophylaxis

- should be considered in all patients with VWD and recurrent bleeding ${ }^{9}$ and

- is required in cases of recurrent, clinically relevant bleeding episodes that affect the quality of life. ${ }^{34,35}$

- Long-term prophylaxis is a possible indication for a VWF concentrate with a low FVIII level. ${ }^{9,32}$

- Depending on the severity and the impact of VWD on the specific patient, long-term prophylaxis should be initiated with two to three infusions of 20 to $50 \mathrm{IU} / \mathrm{kg}$ per week. ${ }^{23}$

- In patients with recurrent GI bleeding due to angiodysplasia, doses of 40 to $60 \mathrm{IU} / \mathrm{kg}$ two to three times a week are recommended. ${ }^{50}$

\section{Procedure during Pregnancy and in the Peri-|Post- natal Period}

Due to the physiological increase of pro-coagulant factors during the course of pregnancy, ${ }^{31}$ pre-existing bleeding conditions in women with VWD type 1 improve in most cases. ${ }^{59}$ Thus, clinically relevant bleeding episodes are rare during pregnancy in patients with VWD type $1,{ }^{59}$ and women with VWF activities $>50 \mathrm{IU} / \mathrm{dL}$ prior to pregnancy onset do not automatically need replacement therapy. Levels reached in the third trimester are maintained during labour (important for the anaesthetist) with a decrease reaching baseline non-pregnancy ranges approximately 1 week after birth. ${ }^{60}$ Larger studies to evaluate the course of FVIII/VWF levels in the peri-partal and post-partal period are needed. Women with VWD type 2 may reach normal VWF Ag level, but VWF is dysfunctional and replacement therapy may become necessary, e.g., to avoid intermittent vaginal bleeding, and may be necessary during delivery. ${ }^{61}$ A special feature of VWD type $2 \mathrm{~B}$ is that a previously existing thrombocytopenia can be aggravated by the increased release of abnormal VWF multimers during pregnancy. ${ }^{61,62}$ Therefore, continuous monitoring of the platelet count is required. VWD type 3 does not achieve a normal VWF activity apart from bleeding episodes during pregancy, and replacement therapy is required during labour and delivery. ${ }^{61,62}$

The risk of spontaneous abortion in women with VWD is comparable to the rates reported in the normal population, ${ }^{63,64}$ but in contrast, the rate of recurrent miscarriage in women with VWD is not clear so far. ${ }^{65}$ In the view of a multifactorial disease, poor endometrial perfusion during the implantation window is reported to be one of the possible causes of recurrent miscarriage. A meta-analysis reported in 2011 including 18 case-control studies in a total of 2,397 women with recurrent miscarriage revealed that angiogenesis- and vasoconstriction-related genes were involved. ${ }^{66}$ Since endothelial VWF regulates angiogenesis ${ }^{67}$ with deficiency states resulting for example in pathological angiodysplasia and vascular malformations with severe GI bleedings, the latter mechanism has to be discussed as one hypothetical reason also in women with recurrent foetal loss.

Evidence regarding replacement with VWF/FVIII products in pregnancy is limited to case reports and case series. ${ }^{61}$ In European recommendations/guidelines, a period of prophylaxis of 3 to 4 days after delivery is recommended unanimously with a VWF:RCo target $>50 \mathrm{IU} / \mathrm{dL}$. $^{6,9,23,32}$ Nevertheless, the optimal duration and frequency of postpartum prophylaxis is unknown. ${ }^{68}$

In addition to the risk of bleeding, the pregnancy-related risk of thrombosis must be taken into consideration. Due to the physiological particularities of the balance of coagulation physiology during pregnancy, ${ }^{31}$ the role of FVIII and D-dimer concentration must be re-evaluated as possible predictors of the risk of thrombosis in this population. The FVIII:C activity can increase to up to approximately $350 \mathrm{IU} / \mathrm{dL}$ in healthy women during pregnancy. ${ }^{31}$ Therefore, an individual approach, in which only the deficient VWF is replaced, seems to be beneficial in patients with VWD.

General Recommendations Regarding Pregnancy and in the Peri-|Post-natal Period

- History of bleeding and family history should be considered.

- VWF:Ag, VWF activity and FVIII:C should be checked prior to invasive procedures, and in certain patients in vitro bleeding time (e.g., platelet function analyzer, PFA) might be useful. ${ }^{69}$ However, evidence regarding FVIII:C and VWF levels, which may require treatment or prophylaxis, is lacking. ${ }^{61}$

- Restrictive use regarding DDAVP is necessary due to possible side effects and interactions, e.g., oxytocin receptor (uterus contraction 68,70 ; tranexamic acid as an alternative).

- In the case of VWF replacement in a prothrombotic situation, a FVIII overload must be avoided and preference should be given to a product with a low FVIII content.

\section{Recommendations Regarding Pregnancy}

- Pregnancy-related reference values should be considered. ${ }^{31}$

- Routine FVIII and VWF level assays should be performed once in each trimester and within 2 weeks before delivery. ${ }^{61}$

\section{Recommendations Regarding Labour/Post-partum Period}

- All women with VWD (including type 1) should give birth in close cooperation with an obstetrician, haematologist, anaesthetist and neonatologist and-in the case of severe VWD-be managed in cooperation with a centre with a blood bank and 24-hour monitoring of FVIII, VWF and maybe in vitro bleeding time (PFA). ${ }^{61,69}$

- Peri-partal therapy such as replacement is rarely required in women with VWD type 1 and VWF:RCo $\geq 50 \mathrm{IU} / \mathrm{dL}$ if no severe bleeding is documented in the patient's medical history. ${ }^{71}$ However, a VWF activity $>50 \mathrm{IU} / \mathrm{dL}$ in week 34 to 36 might be too low in certain women, e.g. women with additional FXIII deficiency.

- During and after delivery, a VWF:RCo of at least $50 \mathrm{IU} / \mathrm{dL}$ and a VWF:RCo dose of $50 \mathrm{IU} / \mathrm{kg}$ once daily for 3 to 4 days are to be aimed at (longer in the case of caesarean delivery) -in individual cases, this procedure can be used for further operations. 
- Blood loss should be documented up to approximately 14 days after delivery (give instructions to the woman if applicable).

- No spinal anaesthesia, e.g. peridural anaesthesia, without replacement in patients with a VWF:RCo $<50 \mathrm{IU} / \mathrm{dL}$ or with a history of severe bleeding (exception: VWD type 1 with normal PFA values and VWF:RCo $\geq 50 \mathrm{IU} / \mathrm{dL}$ ).

\section{Procedure in Paediatrics}

No specific recommendations for replacement therapy in children with VWD can be found in European guidelines, and therefore recommendations for adults must be applied. ${ }^{72}$ In the overall population, the lower reference values (10th percentile) for FVIII:C are 50\% in the first 12 months of life. Between 1 and 18 years, the 10th percentile for FVIII:C were reported as $55 \%$ (1-5 years), 58\% (5.1-10 years) and 48\% (10.1-18 years). ${ }^{31}$ These small differences between the age groups are not clinically relevant for issues regarding VWD. No stratification according to blood groups is available for children.

The indications for the plasma-derived VWF products are not restricted to adults or specific age groups in patients with VWD, although clinical data are limited in children and adolescents. The market authorization for the recombinant VWF is currently limited to adults only. Unlike patients with haemophilia A, pharmacokinetics of the VWF/FVIII concentrates were not found to be age-dependent. ${ }^{13,24}$ There is limited data on the prophylaxis in children with VWD compared with prophylaxis in children with haemophilia. ${ }^{33,35,58}$

\section{Recommendations}

- Children who are likely to require replacement therapy should be vaccinated subcutaneously against hepatitis $\mathrm{A}$ and B. ${ }^{73}$

- Children with VWD who need to undergo surgery or dental interventions should be treated at hospitals with an on-site haemophilia center. ${ }^{73}$

- Short-term prophylaxis is often needed in children with VWD type 3 but may also be required in children with severe type 1 and type $2 .{ }^{35,58,73}$

- In children, depending on the type of VWD, long-term prophylaxis may be applied individually (1-3 times weekly), e.g. in recurrent joint bleeds and possibly in children with recurrent epistaxis. ${ }^{35}$ However, long-term prophylaxis should be restricted to intensive bleeding periods and the indication must be re-evaluated on regular follow-up visits.

- Replacement therapy can be administered at the haemophilia centre or self-administered at home. ${ }^{73}$

\section{Conclusion}

- Decisions on replacement therapy in patients with VWD are to be made individually based on VWD type, history and risk of bleeding and risk of thrombosis as well as the indication (treatment or prophylaxis of bleeding, surgical intervention or labour) and the variable individual VWF and FVIII increase. Other factors such as age and $\mathrm{ABO}$ blood type may be considered.
- Information on dosages and minimum trough levels in guidelines or recommendations are for orientation only and deviations can be considered if justified.

- Clinically relevant side effects of replacement therapy are notably hypersensitivity reactions, the occurrence of inhibitors and thromboembolic complications.

- Dual VWF/FVIII products have advantages when the FVIII levels are low:

- Acute bleeding or during emergency surgery, when usage of free combinations of a VWF and a FVIII product does not seem feasible.

- On-demand usage in the self-treatment setting at home or on vacation.

- A VWF concentrate with a low or zero level of FVIII may be the treatment of first choice in the following situations:

- Repeated infusions in the case of long-term prophylaxis, major bleeding episodes or major surgical interventions.

- Pre-existing risk of thrombosis (age $>70$ years, own history or family history of thromboembolism, obesity, immobility $\geq 3$ days, cardiovascular, malignant or inflammatory disease or cases of coagulation activation, thrombophilia or increased FVIII:C level), pregnancy and labour.

- In the case of short-term replacement for elective surgery, a VWD concentrate with a low level of FVIII can be considered as well.

\section{Conflict of Interest}

U.N.G. declares speaker and/or advisor honoraria. W.M. declares speaker and/or advisor honoraria from Shire, Octapharma, LFB and CSL Behring. J.K. declares speaker and/or advisor honoraria from Aspen, Bayer Health Care Pharmaceuticals, Daiichi Sankyo, Boehringer Ingelheim, CSL Behring, Pfizer, LFB, BMS, Mitsubishi, Roche, Sanofi and Novo Nordisk. C.E.D. declares speaker and/or advisor honoraria from Bayer, Boehringer Ingelheim, Daiichi Pharma, Pfizer and LFB. M.M. declares speaker and/or advisor honoraria from Astra Zeneca, Bayer, CSL Behring, IL-Werfen/TEM International und LFB Biomedicaments. M.v.D.P. declares speaker and/or advisor honoraria from CSL Behring, LFB, Novartis, Octapharma and Shire. D.W. was an employee of LFB GmbH, Münster, from February 2017 to January 2018. M.S. declares speaker and/or advisor honoraria from Bayer, LFB, Novo Nordisk, Pfizer, Shire, Sobi, IL-Werfen and CSL Behring.

\section{Acknowledgment}

The authors thank Dr. med. Detlev Janssen for editorial support. Detlev Janssen declares that his company Med-iScene Concept GmbH, Weisendorf, Germany, received support in this connection by LFB GmbH, Münster, Germany.

\section{References}

1 Sadler JE, Budde U, Eikenboom JC, et al; Working Party on von Willebrand Disease Classification. Update on the pathophysiology and classification of von Willebrand disease: a report of the 
Subcommittee on von Willebrand Factor. J Thromb Haemost 2006;4(10):2103-2114

2 Haberichter SL, Shi Q, Montgomery RR. Regulated release of VWF and FVIII and the biologic implications. Pediatr Blood Cancer 2006;46(05):547-553

3 Vlot AJ, Koppelman SJ, van den Berg MH, Bouma BN, Sixma JJ. The affinity and stoichiometry of binding of human factor VIII to von Willebrand factor. Blood 1995;85(11):3150-3157

4 Stockschlaeder M, Schneppenheim R, Budde U. Update on von Willebrand factor multimers: focus on high-molecular-weight multimers and their role in hemostasis. Blood Coagul Fibrinolysis 2014;25(03):206-216

5 Federici AB. Clinical and laboratory diagnosis of VWD. Hematology (Am Soc Hematol Educ Program) 2014;2014(01):524-530

6 Laffan MA, Lester W, O'Donnell JS, et al. The diagnosis and management of von Willebrand disease: a United Kingdom Haemophilia Centre Doctors Organization guideline approved by the British Committee for Standards on Haematology. Br J Haematol 2014;167(04):453-465

7 Flood VH, Christopherson PA, Gill JC, et al. Clinical and laboratory variability in a cohort of patients diagnosed with type 1 VWD in the United States. Blood 2016;127(20):2481-2488

8 Federici AB, Bucciarelli P, Castaman G, et al. The bleeding score predicts clinical outcomes and replacement therapy in adults with von Willebrand disease. Blood 2014;123(26):4037-4044

9 Castaman G, Goodeve A, Eikenboom J; European Group on von Willebrand Disease. Principles of care for the diagnosis and treatment of von Willebrand disease. Haematologica 2013;98 (05):667-674

10 Franchini M, Mannucci PM. Von Willebrand factor (Vonvendi®): the first recombinant product licensed for the treatment of von Willebrand disease. Expert Rev Hematol 2016;9(09):825-830

11 Mannucci PM. Venous thromboembolism in von Willebrand disease. Thromb Haemost 2002;88(03):378-379

12 CSL Behring GmbH. Fachinformation Haemate ${ }^{\circledR}$ P 250/500/1000, effective January 2018. Available at: www.fachinfo.de. Accessed June 28, 2018

13 CSL Behring GmbH. Fachinformation Voncento, effective April 2018. Available at: www.fachinfo.de. Accessed June 28, 2018

14 Octapharma GmbH. Fachinformation Wilate 500/1000, effective June 2015. Available at: www.fachinfo.de. Accessed June 28, 2018

15 Shire Deutschland GmbH. Fachinformation Immunate 500 I.E./ 1000 I. E., effective May 2018. Available at: www.fachinfo.de. Accessed June 28, 2018

16 Baxalta Innovations $\mathrm{GmbH}$. Fachinformation Veyvondi, effective August 2018. Available at: www.fachinfo.de. Accessed February 17, 2019

17 Goudemand J, Scharrer I, Berntorp E, et al. Pharmacokinetic studies on Wilfactin, a von Willebrand factor concentrate with a low factor VIII content treated with three virus-inactivation/ removal methods. J Thromb Haemost 2005;3(10):2219-2227

18 Gill JC, Castaman G, Windyga J, et al. Hemostatic efficacy, safety, and pharmacokinetics of a recombinant von Willebrand factor in severe von Willebrand disease. Blood 2015;126(17):2038-2046

19 LFB Biomedicaments. Fachinformation Willfact, effective June 2015. www.fachinfo.de. Accessed June 28, 2018

20 Saccullo G, Makris M. Prophylaxis in von Willebrand Disease: coming of age? Semin Thromb Hemost 2016;42(05):498-506

21 Veyvondi: EPAR-Public assessment report 28 June 2018. Available at: https://www.ema.europa.eu/en/documents/assessmentreport/veyvondi-epar-public-assessment-report_en.pdf. Accessed March 10, 2018

22 Borel-Derlon A, Federici AB, Roussel-Robert V, et al. Treatment of severe von Willebrand disease with a high-purity von Willebrand factor concentrate (Wilfactin): a prospective study of 50 patients. J Thromb Haemost 2007;5(06):1115-1124

23 Lassila R, Holme PA, Landorph A, Petrini P, Onundarson PT, Hillarp A. Nordic Haemophilia Council's practical guidelines on diagnosis and management of von Willebrand disease. Semin Thromb Hemost 2011;37(05):495-502

24 Lissitchkov TJ, Buevich E, Kuliczkowski K, et al. Pharmacokinetics, efficacy, and safety of a plasma-derived VWF/FVIII concentrate (VONCENTO) for on-demand and prophylactic treatment in patients with von Willebrand disease (SWIFT-VWD study). Blood Coagul Fibrinolysis 2017;28(02):152-162

25 Kessler CM, Friedman K, Schwartz BA, Gill JC, Powell JS, Wilate PK. The pharmacokinetic diversity of two von Willebrand factor (VWF)/ factor VIII (FVIII) concentrates in subjects with congenital von Willebrand disease. Results from a prospective, randomizsd crossover study. Thromb Haemost 2011;106: 279-288

26 Michiels JJ, Berneman ZN, van der Planken M, Schroyens W, Budde $\mathrm{U}$, van Vliet HH. Bleeding prophylaxis for major surgery in patients with type 2 von Willebrand disease with an intermediate purity factor VIII-von Willebrand factor concentrate (Haemate-P). Blood Coagul Fibrinolysis 2004;15(04):323-330

27 Wissenschaftlicher Beirat der Bundesärztekammer. Querschnitts-Leitlinien zur Therapie mit Blutkomponenten und Plasmaderivaten - Herausgegeben von der Bundesärztekammer auf Empfehlung ihres Wissenschaftlichen Beirats; 4. überarbeitete Auflage; Deutscher Ärzte-Verlag, Köln, 2014

28 Leebeek FWG, Eikenboom JCJ. Von Willebrand's disease. N Engl J Med 2016;375(21):2067-2080

29 Mannucci PM, Franchini M. Von Willebrand's disease. N Engl J Med 2017;376(07):701

30 Di Paola J, Lethagen S, Gill J, et al. Presurgical pharmacokinetic analysis of a von Willebrand factor/factor VIII (VWF/FVIII) concentrate in patients with von Willebrand's disease (VWD) has limited value in dosing for surgery. Haemophilia 2011;17(05): 752-758

31 Nowak-Göttl U, Limperger V, Kenet G, et al. Developmental hemostasis: A lifespan from neonates and pregnancy to the young and elderly adult in a European white population. Blood Cells Mol Dis 2017;67:2-13

32 Mannucci PM, Franchini M, Castaman G, Federici AB; Italian Association of Hemophilia Centers. Evidence-based recommendations on the treatment of von Willebrand disease in Italy. Blood Transfus 2009;7(02):117-126

33 Abshire TC, Federici AB, Alvárez MT, et al; VWD PN. Prophylaxis in severe forms of von Willebrand's disease: results from the von Willebrand Disease Prophylaxis Network (VWD PN). Haemophilia 2013;19(01):76-81

34 Berntorp E, Petrini P. Long-term prophylaxis in von Willebrand disease. Blood Coagul Fibrinolysis 2005;16(Suppl 1):S23-S26

35 Halimeh S, Krümpel A, Rott $\mathrm{H}$, et al. Long-term secondary prophylaxis in children, adolescents and young adults with von Willebrand disease. Results of a cohort study. Thromb Haemost 2011;105(04):597-604

36 Batlle J, López-Fernández MF, Fraga EL, Trillo AR, Pérez-Rodríguez MA. Von Willebrand factor/factor VIII concentrates in the treatment of von Willebrand disease. Blood Coagul Fibrinolysis 2009; 20(02):89-100

37 Jenkins PV, Rawley O, Smith OP, O'Donnell JS. Elevated factor VIII levels and risk of venous thrombosis. Br J Haematol 2012;157(06): 653-663

38 Miesbach W, Berntorp E. Von Willebrand disease - the 'dos' and 'don'ts' in surgery. Eur J Haematol 2017;98(02):121-127

39 Coppola A, Franchini M, Makris M, Santagostino E, Di Minno G, Mannucci PM. Thrombotic adverse events to coagulation factor concentrates for treatment of patients with haemophilia and von Willebrand disease: a systematic review of prospective studies. Haemophilia 2012;18(03):e173--e187

40 Girolami A, Tasinato V, Sambado L, Peroni E, Casonato A. Venous thrombosis in von Willebrand disease as observed in one centre and as reported in the literature. Blood Coagul Fibrinolysis 2015; 26(01):54-58 
41 Gill JC, Mannucci PM. Thromboembolic incidence with transiently elevated levels of coagulation factors in patients with von Willebrand disease treated with VWF:FVIII concentrate during surgery. Haemophilia 2014;20(06):e404-e406

42 Franchini M, Veneri D, Poli G, Manzato F, Salvagno GL, Lippi G. High prevalence of inherited prothrombotic risk factors in 134 consecutive patients with von Willebrand disease. Am J Hematol 2006;81(06):465-467

43 Makris M, Colvin B, Gupta V, Shields ML, Smith MP. Venous thrombosis following the use of intermediate purity FVIII concentrate to treat patients with von Willebrand's disease. Thromb Haemost 2002;88(03):387-388

44 Encke A, Haas S, Koop I, et al. (2015) S3-Leitlinie Prophylaxe der venösen Thromboembolie (VTE). 2. Komplett überarbeitete Auflage, Stand: 15.10.2015. Available at: http://www.awmf.org/ leitlinien/detail/1l/003-001.html. Accessed July 14, 2016

45 Nichols WL, Hultin MB, James AH, et al. von Willebrand disease (VWD): evidence-based diagnosis and management guidelines, the National Heart, Lung, and Blood Institute (NHLBI) Expert Panel report (USA). Haemophilia 2008;14(02):171-232

46 Makris M, Federici AB, Mannucci PM, et al. The natural history of occult or angiodysplastic gastrointestinal bleeding in von Willebrand disease. Haemophilia 2015;21(03):338-342

47 Ragni MV, Machin N, James AH, et al. Feasibility of the Von Willebrand disease PREVENT trial. Thromb Res 2017;156:8-13

48 Federici AB, Castaman G, Franchini M, et al. Clinical use of Haemate $P$ in inherited von Willebrand's disease: a cohort study on 100 Italian patients. Haematologica 2007;92(07):944-951

49 Berntorp E, Windyga J; European Wilate Study Group. Treatment and prevention of acute bleedings in von Willebrand diseaseefficacy and safety of Wilate, a new generation von Willebrand factor/factor VIII concentrate. Haemophilia 2009;15(01):122-130

50 Franchini M, Mannucci PM. Gastrointestinal angiodysplasia and bleeding in von Willebrand disease. Thromb Haemost 2014;112 (03):427-431

51 Mannuccio Mannucci P, Kyrle PA, Schulman S, Di Paola J, Schneppenheim R, Cox Gill J. Prophylactic efficacy and pharmacokinetically guided dosing of a von Willebrand factor/factor VIII concentrate in adults and children with von Willebrand's disease undergoing elective surgery: a pooled and comparative analysis of data from USA and European Union clinical trials. Blood Transfus 2013;11(04):533-540

52 van Galen KPM, Meijer K, Vogely HC, et al; WiN study group. Joint surgery in von Willebrand disease: a multicentre cross-sectional study. Haemophilia 2016;22(02):256-262

53 Federici AB. Prophylaxis in patients with von Willebrand disease: who, when, how? J Thromb Haemost 2015;13(09):1581-1584

54 Holm E, Carlsson KS, Lövdahl S, Lail AE, Abshire TC, Berntorp E. Bleeding-related hospitalization in patients with von Willebrand disease and the impact of prophylaxis: results from national registers in Sweden compared with normal controls and participants in the von Willebrand Disease Prophylaxis Network. Haemophilia 2018;24(04):628-633

55 Lethagen S. Clinical experience of prophylactic treatment in von Willebrand disease. Thromb Res 2006;118(Suppl 1):S9-S11
56 Tosetto A, Castaman G, Rodeghiero F. Assessing bleeding in von Willebrand disease with bleeding score. Blood Rev 2007;21(02): 89-97

57 Ragni MV, Machin N, Malec LM, et al. Von Willebrand factor for menorrhagia: a survey and literature review. Haemophilia 2016; 22(03):397-402

58 Holm E, Abshire TC, Bowen J, et al. Changes in bleeding patterns in von Willebrand disease after institution of long-term replacement therapy: results from the von Willebrand Disease Prophylaxis Network. Blood Coagul Fibrinolysis 2015;26(04):383-388

59 Scholz U, Oppermann J, Siegemund A, Schobess R. Von Willebrand disease type 1 and pregnancy [in German]. Hamostaseologie 2011;31(Suppl 1):S11-S13

60 James AH, Konkle BA, Kouides P, et al. Postpartum von Willebrand factor levels in women with and without von Willebrand disease and implications for prophylaxis. Haemophilia 2015;21(01): 81-87

61 Reynen E, James P. Von Willebrand disease and pregnancy: a review of evidence and expert opinion. Semin Thromb Hemost 2016;42(07):717-723

62 Castaman G. Changes of von Willebrand factor during pregnancy in women with and without von Willebrand disease. Mediterr J Hematol Infect Dis 2013;5(01):e2013052

63 Nybo Andersen AM, Wohlfahrt J, Christens P, Olsen J, Melbye M. Maternal age and fetal loss: population based register linkage study. BMJ 2000;320(7251):1708-1712

64 Blohm F, Fridén B, Milsom I. A prospective longitudinal population-based study of clinical miscarriage in an urban Swedish population. BJOG 2008;115(02):176-182, discussion 183

65 Skeith L, Rydz N, O'Beirne M, Goodyear D, Li H, Poon MC. Pregnancy loss in women with von Willebrand disease: a single-center pilot study. Blood Coagul Fibrinolysis 2017;28(05): 393-397

66 Su MT, Lin SH, Chen YC. Genetic association studies of angiogenesis- and vasoconstriction-related genes in women with recurrent pregnancy loss: a systematic review and meta-analysis. Hum Reprod Update 2011;17(06):803-812

67 Starke RD, Ferraro F, Paschalaki KE, et al. Endothelial von Willebrand factor regulates angiogenesis. Blood 2011;117(03): 1071-1080

68 Federici $A B$, Königs $C$, James $A H$. Contemporary issues in the management of von Willebrand disease. Thromb Haemost 2016; 116(Suppl 1):S18-S25

69 Mannucci PM, Federici AB. Management of inherited von Willebrand disease. Best Pract Res Clin Haematol 2001;14(02): 455-462

70 Fachinformation Minirin parenteral 2019

71 James AH, Eikenboom J, Federici AB. State of the art: von Willebrand disease. Haemophilia 2016;22(Suppl 5):54-59

72 Castaman G, Linari S. Human von Willebrand factor/factor VIII concentrates in the management of pediatric patients with von Willebrand disease/hemophilia A. Ther Clin Risk Manag 2016; 12:1029-1037

73 Williams M, Patel J. Von Willebrand Disease: diagnosis and management. Paediatr Child Health 2015;25(08):354-359 